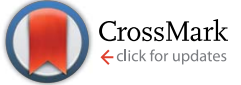

Cite this: RSC Adv., 2017, 7, 15321
Received 6th February 2017

Accepted 1st March 2017

DOI: 10.1039/c7ra01511a

rsc.li/rsc-advances

\section{Ferrous complexes supported by sterically encumbered asymmetric bis(arylimino) acenaphthene (BIAN) ligands: synthesis, characterization and screening for catalytic hydrosilylation of carbonyl compounds ${ }^{\dagger}$}

\begin{abstract}
Xun Yu, Feifeng Zhu,\$ Donglei Bu and Hao Lei*
Six ferrous chloride complexes (( $\left.\mathrm{Ar}-\mathrm{BIAN}^{\mathrm{X}}\right) \mathrm{FeCl}_{2}$ : $\mathrm{Ar}=2,6$-diisopropylphenyl (Dipp), $\mathrm{X}=\mathrm{F}$ (1), $\mathrm{Cl}$ (2), $\mathrm{Me}$ (3); $\mathrm{Ar}=$ mesityl (Mes), X = F (4), $\mathrm{Cl}(5), \mathrm{Me}(6))$ supported by sterically bulky asymmetric bis(arylimino) acenaphthene (BIAN) ligands were prepared through the treatment of anhydrous $\mathrm{FeCl}_{2}$ with the corresponding ligands in a molar ratio of $1: 1$. The compounds were characterized by $\mathrm{X}$-ray crystallography, IR, NMR and electrochemical methods. This series of complexes represents rare examples of structurally characterized iron compounds bearing asymmetric bidentate BIAN ligands. The complexes were tested for catalytic hydrosilylation of aldehydes and ketones at room temperature, and moderate to good yields of alcohol derivatives were obtained after hydrolysis workup.
\end{abstract}

\section{Introduction}

Within the last decade, considerable attention has been directed towards metal complexes supported by redox-active ligands, ${ }^{\mathbf{1 , 2}}$ owing to their intriguing electronic structures and potential applications in catalysis. ${ }^{3-7}$ Due to the multiple consecutive oxidation states of redox-active ligands, their coordination to metal centers usually induces radical reactivity and electron reservoir behavior. $\alpha$-Diimines comprise a class of the most widely investigated redox-active ligands, demonstrating three different oxidation states in their coordination chemistry, i.e. the neutral ligand, radical anion and the dianionic form. ${ }^{89}$ The electronic and steric properties of their metal compounds can be regulated by variation of the substituents on the $\mathrm{N}-\mathrm{C}-\mathrm{C}-\mathrm{N}$ backbone. Specifically, when the backbone $\mathrm{C}-\mathrm{C}$ bond is fused with a conjugated naphthalene ring, a rigid and robust ligand framework is derived, i.e. bis(arylimino)acenaphthene (BIAN). Similar to the parent diimine ligand sets, BIAN ligands can also undergo successive facile single-electron reductions. Furthermore, the neutral form of BIAN ligands can accept up to four electrons, due to the incorporation of naphthalene fragment. In addition, the rigid

\footnotetext{
Department of Chemistry, College of Chemistry and Materials Science, Jinan University, Guangzhou 510632, China.E-mail: tleihao@jnu.edu.cn

$\dagger$ Electronic supplementary information (ESI) available: NMR spectra, UV-vis spectra, cyclic voltammograms and CIFs for compounds 1-6. CCDC 1530839-1530844. For ESI and crystallographic data in CIF or other electronic format see DOI: 10.1039/c7ra01511a

\$ These authors contributed equally to this work.
}

and planar ligand backbone ensures the two nitrogen donor atoms chelating to the same metal center in a syn conformation, which are crucial for the preparation of certain single-metal catalysts. $^{10}$

Synthesis and reactivity of metal BIAN compounds are well documented in the literature. For instance, metal-to-ligand charge transfer was commonly observed in a series of heavier p-block metal compounds supported by BIAN ligands. ${ }^{11-15}$ In recent years, Clark and co-authors explored the reactivity and redox capability of BIAN ligands in early transition metal complexes, revealing very rich electronic behavior for such metal/ligand combination. ${ }^{\mathbf{1 6}, 17}$ In contrast, iron compounds bearing BIAN ligand framework are relatively less investigated. A search in Cambridge Structural Database (CSD) showed that only several structurally characterized BIAN-Fe complexes have been reported, including those with tridentate BIAN ligands with an additional donor arm other than the two $\mathrm{N}$ donors. ${ }^{18} \mathrm{It}$ was discovered that the solid-state structures of these tridentate BIAN metal complexes exhibited a range of coordination modes depending on the crystallization solvent as well as the nucleophilicity of the third donor atoms. ${ }^{19}$ Other known BIAN-Fe compounds usually involve identical aryl $\mathrm{N}$-substituents (Mes or Dipp), featuring mononuclear, ${ }^{20,21}$ dinuclear $^{22}$ or multinuclear structural motifs. ${ }^{23}$ It was discovered that the radical anionic form of BIAN ligands could be installed to Fe(II) centers through the treatment of $\mathrm{FeI}_{2}$ with various molar ratio of potassium salt of the radical anion. ${ }^{22}$ Findlater and co-workers reported the structure of a toluene-capped low-valent iron complex supported by a partially reduced BIAN ligand, i.e. (BIAN)Fe $\left(\eta^{6}-\mathrm{C}_{7} \mathrm{H}_{8}\right)$, synthesized via reduction of the ferrous 
precursor with sodium amalgam. ${ }^{20}$ This compound was shown to be an efficient precatalyst for the hydrosilylation of aldehydes and ketones using $\mathrm{Ph}_{2} \mathrm{SiH}_{2}$ at $70{ }^{\circ} \mathrm{C}$. Very recently, similar $\left({ }^{\mathrm{Ar}} \mathrm{BIAN}\right) \mathrm{FeBr}_{2}$ complexes $(\mathrm{Ar}=$ Mes or Dipp) were reported by Hoyt and co-workers, and the catalytic hydrosilylation of 1hexene was investigated. ${ }^{21}$

Reduction of carbonyl compounds is among the most valuable synthetic routes in both academia and industry. Transition-metal-catalyzed hydrosilylation followed by hydrolysis workup has emerged as a useful protocol for the production of alcohols. ${ }^{24}$ Although the platinum group metals have long been proved to be efficient for such transformations, their high cost and toxicity prompts the search for more sustainable homogeneous catalytic systems. Complexes with earthabundant metals (in particular Fe) have attracted increasing attention in recent years, due to their potential as alternative cheap catalysts for various organic transformations. ${ }^{25-28}$ During the last decade, rapid developments have occurred in the area of Fe-catalyzed hydrosilylation of aldehydes and ketones, as a result of the efforts from the research groups of Beller, ${ }^{29}$ Nishiyama, ${ }^{30}$ Guan, ${ }^{31}$ Chirik, ${ }^{32,33}$ Tilley, ${ }^{34}$ Gade $^{35,36}$ and others. ${ }^{37,38}$ In spite of such considerable development in this area, examples of Fe-catalyzed hydrosilylation of carbonyls under mild conditions (e.g. at room temperature) are still limited to several recent reports. ${ }^{32-38}$ These include iron compounds bearing tridentate $\mathrm{NNN}^{32,33,35}$ or $\mathrm{NNO}^{37}$ pincer ligands, as well as those featuring two- ${ }^{34}$ or three-coordinate ${ }^{38} \mathrm{Fe}$ centers, the preparation of which usually involves sophisticated ligand design and multiple synthetic steps. Very recently, Gade and co-workers reported highly active iron alkyl and alkoxide catalysts with turnover frequency (TOF) up to $240 \mathrm{~h}^{-1}$ at $-40^{\circ} \mathrm{C}$ for hydrosilylation reactions. ${ }^{35,36}$ In this context, discovery of easily-prepared Fe-containing hydrosilylation catalysts that function at room temperature (or lower) still remains a current challenge in this research area.

As mentioned earlier, a BIAN supported Fe complex has been reported to efficiently catalyze the hydrosilylation of aldehydes and ketones at $70{ }^{\circ} \mathrm{C}$ under solvent-free condition. ${ }^{20}$ It is reasonable to assume that increasing the steric bulk at $\mathrm{N}$ atoms on the BIAN backbone, might further stabilize the proposed Fe hydride catalytic intermediate, thus improves the efficiency of this catalytic system. In recent years, 2,6-dibenzhydryl phenyl substituents (abbreviated as Ar*) were introduced to the BIAN ligand framework by Sun and others, and their nickel and palladium complexes were demonstrated to be effective catalysts for either ethylene polymerization or $\mathrm{C}-\mathrm{C}$ cross coupling reactions. ${ }^{39-45}$ Following our previous assumption, herein we report the synthesis of a series of $\mathrm{Fe}(\mathrm{II})$ complexes supported by sterically hindered BIAN ligands $\left(\operatorname{Ar}-\mathrm{BIAN}^{\mathrm{X}}\right) \mathrm{FeCl}_{2}(\mathrm{Ar}=\mathrm{Dipp}, \mathrm{X}$ $=\mathrm{F}$ (1), $\mathrm{Cl}$ (2), Me (3); $\mathrm{Ar}=\mathrm{Mes}, \mathrm{X}=\mathrm{F}$ (4), Cl (5), Me (6)). The solid-state structures of the six compounds were determined by single crystal X-ray diffraction, rendering them rare examples of structurally characterized iron complexes with asymmetric BIAN ligands. The new compounds were further demonstrated to be efficient precatalysts for room temperature hydrosilylation of various aldehyde and ketone substrates.

\section{Results and discussion}

The asymmetric bulky BIAN ligands are facile to prepare via stepwise condensation of acenaphthaquinone with anilines under acid-catalyzed conditions (Scheme 1). ${ }^{42-45}$ In the current study, we chose to employ BIAN ligands that have two different substituted aryl groups on the $\mathrm{N}$ donor atoms. In a certain ligand framework, one of the nitrogen atoms is substituted with Mes or Dipp group, while the other $\mathrm{N}$ atom is bonded to a sterically encumbered 2,6-dibenzhydryl phenyl group (Ar*), whose para-position is occupied by different electron donating or withdrawing groups $(-\mathrm{F},-\mathrm{Cl}$ or $-\mathrm{Me})$. Thus, such ligand design strategy results in a series of asymmetric bulky BIAN ligands with tunable electronic property and steric bulk.

Treatment of the bulky BIAN ligands with anhydrous $\mathrm{FeCl}_{2}$ in THF at room temperature afforded the corresponding ferrous complexes 1-6 in good yields (Scheme 1). Although crystal structures of 1-6 revealed different extent of solvation with THF molecules (either coordinated or non-coordinated, vide infra), the elemental analysis data confirmed their formula composition as $\left(\mathrm{Ar}^{-B I A N^{\mathrm{X}}}\right) \mathrm{FeCl}_{2}$. All six compounds showed very high thermal stability under inert atmosphere, with melting points higher than $320{ }^{\circ} \mathrm{C}$. The ${ }^{1} \mathrm{H}$ NMR spectra of these compounds were featured with broadened and paramagnetically shifted resonances within the range of -16 to $+18 \mathrm{ppm}$ (see ESI $\dagger$ ), suggesting high-spin electron configuration for the iron centers. This is similar to the observation for previously reported analogous BIAN Fe(II) halide complexes..$^{20,21}$

The new ferrous complexes were further characterized by IR spectroscopy. As summarized in Table 1 , the $\mathrm{C}=\mathrm{N}$ stretching

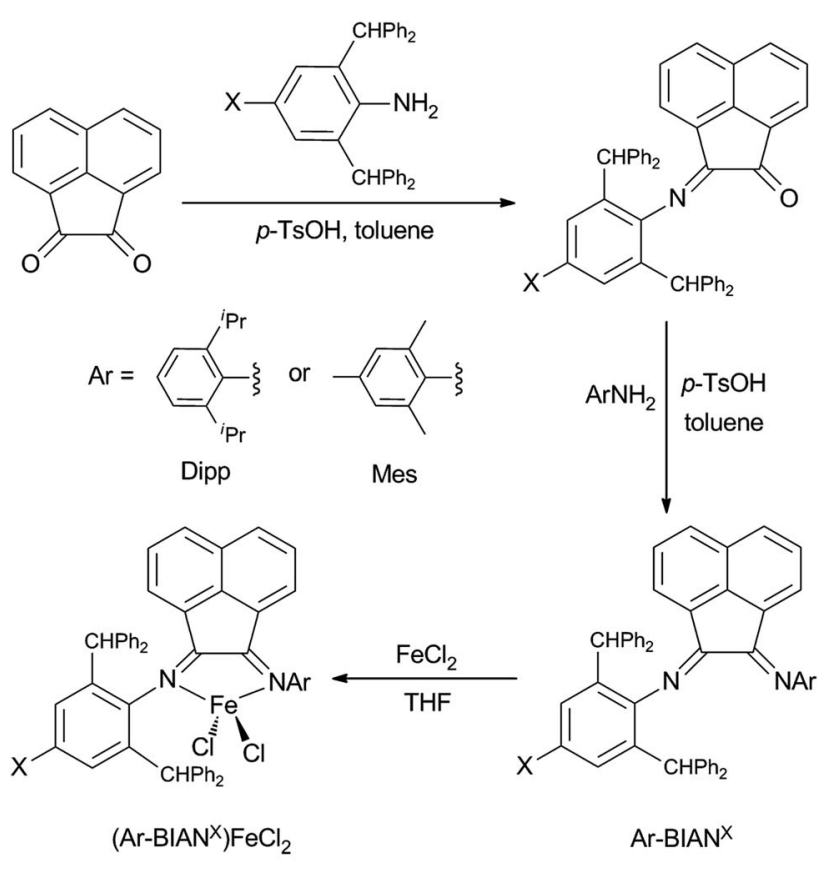

$A r=\operatorname{Dipp}, X=F(1), C l(2)$ or $M e(3)$
$A r=M e s, X=F(4), C l(5)$ or $M e(6)$

Scheme 1 Synthetic routes to complexes 1-6. 
Table 1 Comparison of $\mathrm{C}=\mathrm{N}$ stretching frequencies for $\mathrm{BIAN}$ ligands and Fe complexes 1-6

\begin{tabular}{lll}
\hline & $\nu(\mathrm{C}=\mathrm{N}) / \mathrm{cm}^{-1}$ & \\
\cline { 2 - 3 } & BIAN ligands & Fe complexes \\
\hline $\mathbf{1}$ & 1639,1593 & 1619,1582 \\
$\mathbf{2}$ & 1640,1595 & 1621,1584 \\
$\mathbf{4}$ & 1631,1590 & 1622,1585 \\
$\mathbf{5}$ & 1643,1593 & 1619,1587 \\
$\mathbf{6}$ & 1642,1598 & 1623,1588 \\
& 1640,1594 & 1621,1586
\end{tabular}

frequencies of the iron compounds are lower than those of the corresponding neutral BIAN ligands, indicating the presence of bonding interactions between imine groups and the metal centers. In addition, the relatively small shifts of the stretching frequencies between the ligands and corresponding iron complexes $\left(\Delta \nu(\mathrm{C}=\mathrm{N})<25 \mathrm{~cm}^{-1}\right)$ imply that no significant metalto-ligand electron transfer has occurred, and the coordinated BIAN ligands all remain in their neutral oxidation states. A closer look at the IR data revealed that all the six Fe compounds showed comparable $\mathrm{C}=\mathrm{N}$ vibration frequencies $(\Delta \nu(\mathrm{C}=\mathrm{N})<10$ $\left.\mathrm{cm}^{-1}\right)$, indicating the presence of similar electronic structures across this series of metal complexes. Furthermore, the $\mathrm{C}=\mathrm{N}$ stretching frequencies of these Fe species were consistent with the reported values for the $\mathrm{Ni}$ and $\mathrm{Pd}$ complexes bearing the same ligand sets, ${ }^{42-45}$ but lower than that reported for analogous Fe compounds with symmetric BIAN ligands. ${ }^{21}$

The electronic structures of the BIAN supported $\mathrm{Fe}$ complexes were also probed by UV-vis spectroscopy. In the spectra (see ESI $\dagger$ ), each of the complexes showed a shoulder absorption band around $c a .420 \mathrm{~nm}$, which is probably a result of the $\mathrm{n} \rightarrow \pi^{*}$ transition from the diimine to the acenaphthene. In contrast, the high energy absorption bands around ca. $320 \mathrm{~nm}$ for the complexes were tentatively assigned to the $\pi \rightarrow$ $\pi^{*}$ transition within the BIAN ligand framework. This is in good comparison to those reported for related BIAN indium compounds. ${ }^{14}$ Again, the similarity of the electronic transition energy for the six ferrous complexes confirmed their comparable electronic structures.

The compositions and solid-state structures of complexes 16 were further corroborated by X-ray crystallography. Vapor diffusion of $n$-hexane into the THF solution of these complexes afforded bronze crystals of high quality. Compound 1 crystallizes in the orthorhombic space group $P 2_{1} 2_{1} 2_{1}$, while compound 3 crystallizes in the triclinic space group $P \overline{1}$. The other four iron complexes all crystallizes in monoclinic space groups, i.e. $P 2_{1} / n$ for compounds 2 and $\mathbf{4}$, and $P 2_{1} / c$ for compounds 5 and $\mathbf{6}$. The crystallographic data and collection parameters are presented in Table 2. In general, all six structures showed expected bonding environment and atom connectivity, with two $\mathrm{N}$ atoms coordinated to the iron center of a ferrous dichloride unit (Fig. 1). However, to our surprise, two different types of coordination environment for the Fe centers were observed, i.e. fourcoordinate (as in complexes 2, 3, 4 and 6) and five-coordinate (as in complexes $\mathbf{1}$ and 5). The major difference between these two bonding situations is whether a THF molecule is directly coordinated to the iron through its oxygen atom. The four-coordinate compounds showed a distorted tetrahedral geometry with calculated $\tau_{4}$ values in the range of 0.83 to $0.88 .^{46}$ In contrast, the five-coordinate complexes demonstrated a more distorted trigonal bipyramidal geometry $\left(\tau_{5}=0.61-0.65\right),{ }^{47}$ with the equatorial positions occupied by two chlorine atoms and one nitrogen atom, while the axial positions occupied by the other nitrogen atom and the oxygen atom of coordinated THF molecule. The fact that some of this series of Fe compounds could adopt a fivecoordinate environment indicates that in this case the effective steric bulk of the Ar* substituent is not as great as originally assumed. This is further supported by the observation that in the structure of $\mathbf{1}$, the THF molecule coordinates to Fe from the same side as the Ar* group, while in the structure of 5 , the coordinated THF molecule lies on the same side of the Mes group. This implies that within the BIAN ligand scaffold, the steric bulk follows the sequence of Dipp $>\mathrm{Ar}^{*}>$ Mes. It is reasonable to deduce that using Ar* groups on both coordinating $\mathrm{N}$ atoms of the BIAN ligands would enforce a much more hindered coordination environment and ensure low-coordination at the iron center. However, such symmetric doubly Ar*-substituted BIAN ligands could not be prepared using conventional acid-catalyzed condensation methods, in accordance with previous literature reports..$^{39}$ It is also noteworthy that for this series of compounds, whether or not to have an additional coordinated THF in the structures does not seem to be affected by the electronic property of remote ligand substituents $(\mathrm{X}=\mathrm{F}, \mathrm{Cl}$ or $\mathrm{Me})$, nor by the difference in steric bulk of the other $N$ substituent (Dipp $v s$. Mes). This implies that the isolation of both 4- and 5-coordinate $\mathrm{Fe}$ complexes across this series might be a result of intermolecular forces during crystallization (e.g. packing effect).

Selected bond distances for the solid-state structures of 1-6 are summarized in Table 3. For metal complexes with redoxactive $\alpha$-diimine or BIAN ligands, inspections of the bond lengths of their $\mathrm{N}_{\mathrm{im}}-\mathrm{C}_{\mathrm{im}}-\mathrm{C}_{\mathrm{im}}-\mathrm{N}_{\mathrm{im}}$ backbones could establish the oxidation state of the ligands. The $\mathrm{C}_{\mathrm{im}}-\mathrm{C}_{\mathrm{im}}$ distances in the structures of 1-6 (1.516-1.531 $\mathrm{\AA})$ are consistent with the values for typical $\mathrm{C}_{\mathrm{sp} 2}-\mathrm{C}_{\mathrm{sp} 2}$ single bond. The $\mathrm{C}_{\mathrm{im}}-\mathrm{N}_{\mathrm{im}}$ bond lengths (1.274-1.289 ̊) unambiguously indicate $\mathrm{C}=\mathrm{N}$ double bond character. Thus, the bonding scheme clearly shows that the BIAN ligands remain in their neutral diimine form in this series of Fe compounds. The molecular structures of the 4-coordinate complexes (2, 3, 4 and 6) feature almost identical $\mathrm{Fe}-\mathrm{N}_{\mathrm{im}}$ bond distances (2.13-2.15 $\mathrm{\AA})$. In contrast, one of the $\mathrm{Fe}-\mathrm{N}_{\mathrm{im}}$ bonds in each 5-coordinate complexes are significantly elongated (2.294(2) $\AA$ for 1 and 2.343(2) $\AA$ for 5), as a result of the coordination of a THF molecule to the metal center. The THF coordination also leads to slightly longer $\mathrm{Fe}-\mathrm{Cl}$ bonds in $\mathbf{1}$ and $\mathbf{5}$ $(2.26-2.29 \AA)$ than those in $2,3,4$ and $6(2.21-2.23 \AA)$.

The electrochemical behavior of the iron complexes 1-6 was investigated by cyclic voltammetry (CV) as shown in Table 4 . All six compounds show similar redox properties and the voltammogram of 2 in dichloromethane was illustrated in Fig. 2 as a representative example. The quasi-reversible redox wave centered at $c a .-0.5 \mathrm{~V}(v s . \mathrm{Ag} / \mathrm{AgCl})$ are tentatively assigned to a two-electron process involving the partial reduction of both 
Table 2 Crystallographic data and collection parameters for complexes 1-6

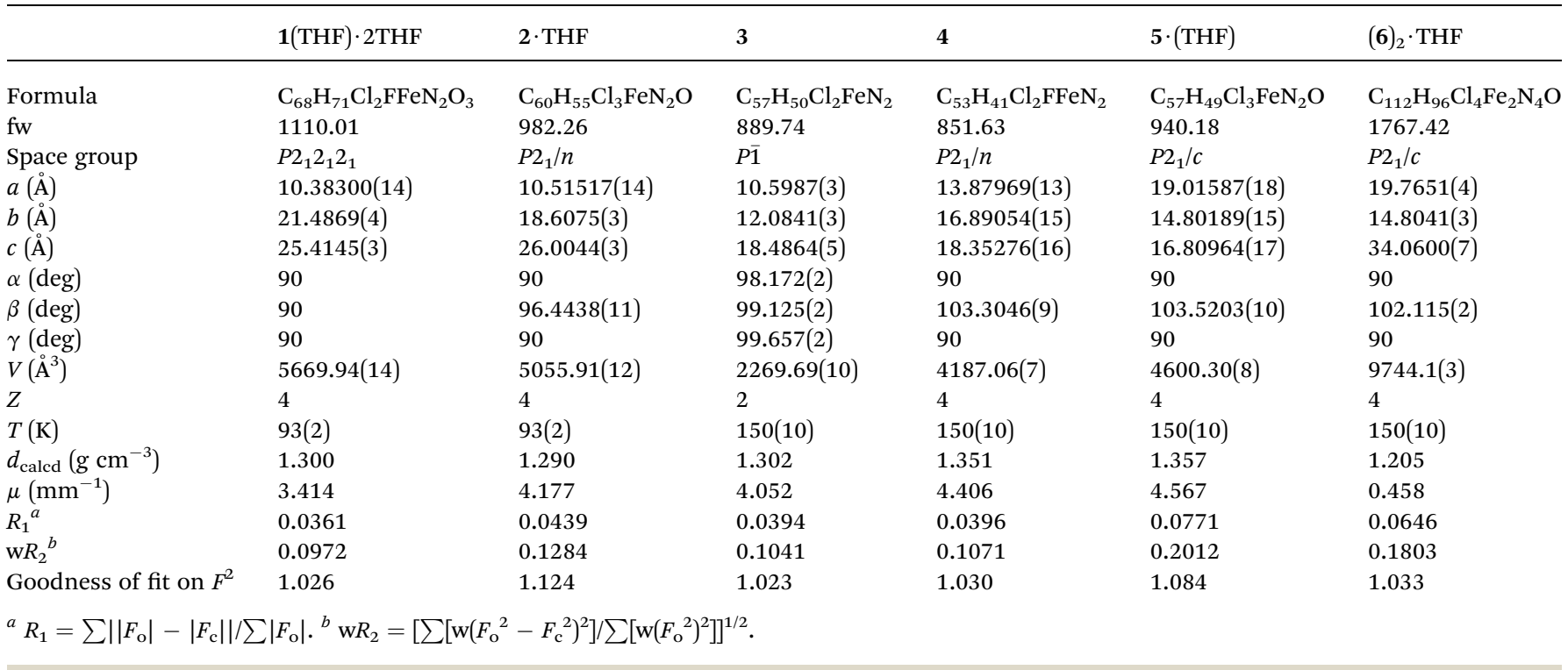

(a)

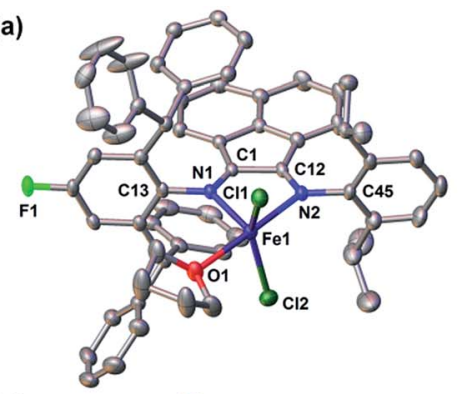

(d)

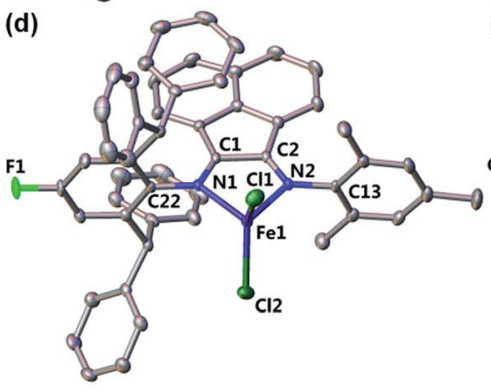

(b)

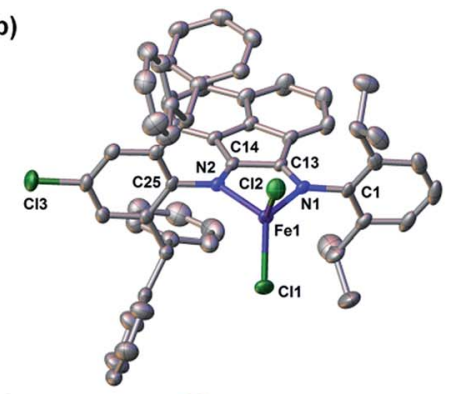

(e)
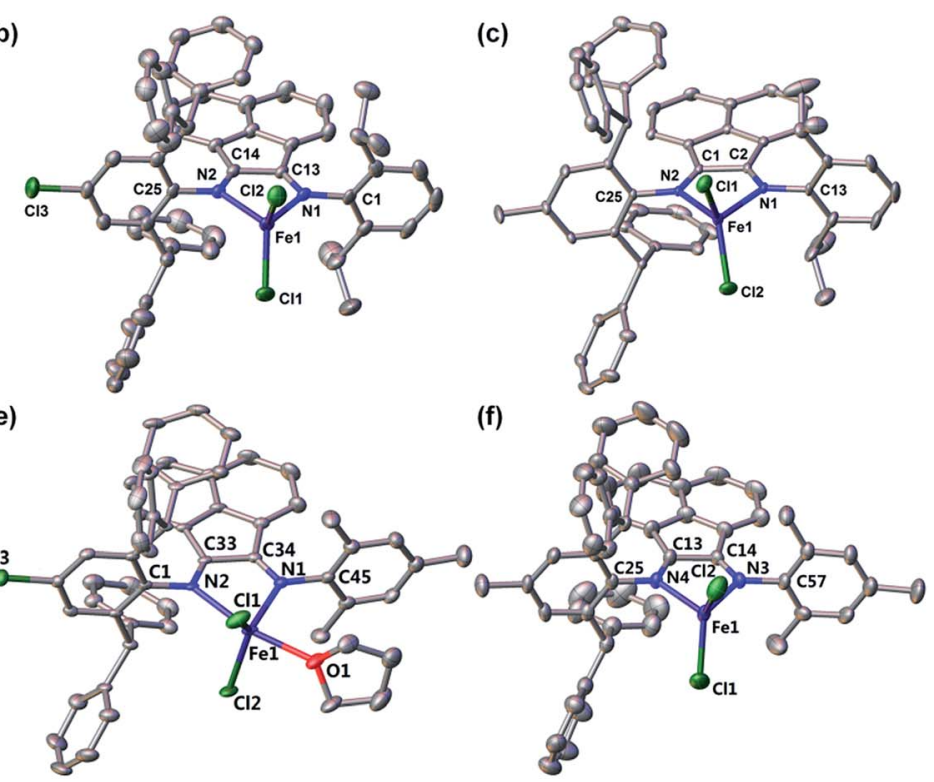

Fig. 1 Solid-state structures of complexes 1-6 (from (a) to (f)) with hydrogen atoms omitted for clarity. The thermal ellipsoids are shown at 30\% probability level.

$\mathrm{Fe}(\mathrm{II})$ center and neutral BIAN ligand. The detection of this $2 \mathrm{e}$ reduction process rather than two separate 1e ligand reductions, is consistent with the previously reported chemical reduction and isolation of (BIAN)Fe $\left(\eta^{6}-\mathrm{C}_{7} \mathrm{H}_{8}\right),{ }^{20}$ which is a formally $2 \mathrm{e}$ reduction product. Furthermore, the half wave potentials $\left(E_{1 / 2}=1 / 2\left(E_{\mathrm{p}}(\mathrm{ox})+E_{\mathrm{p}}(\right.\right.$ red $\left.\left.)\right)\right)$ for the two fluorinated derivatives $1(-0.493 \mathrm{~V} v s . \mathrm{Ag} / \mathrm{AgCl})$ and $4(-0.480 \mathrm{~V} v s . \mathrm{Ag} / \mathrm{AgCl})$ are the most positive ones among this series of Fe compounds, in accordance with the strong electron-withdrawing ability of fluorine atoms. Consistently, complexes $\mathbf{3}$ and $\mathbf{6}$, whose supporting BIAN ligands contain electron-donating methyl substituents, show the most negative $E_{1 / 2}$ values at $-0.592 \mathrm{~V}$ and $-0.616 \mathrm{~V}(v s . \mathrm{Ag} / \mathrm{AgCl})$, respectively. This demonstrates that subtle modification at the $N$-aryl group of BIAN skeleton can effectively modulate the redox potential of the corresponding BIAN metal complexes within a considerably wide range ( $c a .136$ $\mathrm{mV}$ ). As shown in Fig. 2, another quasi-reversible redox wave at a more positive potential $(c a .0 .1 \mathrm{~V} v s . \mathrm{Ag} / \mathrm{AgCl})$ was observed, which are attributed to the $1 \mathrm{e}$ process of $\mathrm{Fe}(\mathrm{II} / \mathrm{Fe}(\mathrm{III})$ couple. In addition, an irreversible reduction wave could be observed at $c a$. $-1.6 \mathrm{~V} v s$. $\mathrm{Ag} / \mathrm{AgCl}$ for complexes 1 and 4 (see ESI $\dagger$ ), which can be ascribed to a further $2 \mathrm{e}$ reduction of the BIAN ligand.

With complexes 1-6 synthesized and fully characterized, we then turned our attention to evaluating the performance of these compounds as precatalysts for room-temperature hydrosilylation of aldehydes and ketones. The initial screening was 
Table 3 Selected bond distances $(\AA)$ and structural parameters for complexes 1-6

\begin{tabular}{|c|c|c|c|c|c|c|}
\hline & 1 & 2 & 3 & 4 & 5 & 6 \\
\hline $\mathrm{C}_{\mathrm{im}}-\mathrm{C}_{\mathrm{im}}$ & $1.521(4)$ & $1.516(3)$ & $1.531(2)$ & $1.522(2)$ & $1.520(4)$ & $1.523(4)$ \\
\hline $\mathrm{C}_{\mathrm{im}}-\mathrm{N}_{\mathrm{im}}$ & $\begin{array}{l}1.289(4) \\
1.274(4)\end{array}$ & $\begin{array}{l}1.286(3) \\
1.279(3)\end{array}$ & $\begin{array}{l}1.282(2) \\
1.275(2)\end{array}$ & $\begin{array}{l}1.284(2) \\
1.279(2)\end{array}$ & $\begin{array}{l}\text { 1.281(4), } \\
1.274(4)\end{array}$ & $\begin{array}{l}1.284(4) \\
1.278(4)\end{array}$ \\
\hline $\mathrm{Fe}-\mathrm{N}_{\mathrm{im}}$ & $\begin{array}{l}2.294(2), \\
2.144(2)\end{array}$ & $\begin{array}{l}2.1455(18), \\
2.1290(18)\end{array}$ & $\begin{array}{l}2.1386(14), \\
2.1371(15)\end{array}$ & $\begin{array}{l}2.1501(15), \\
2.1367(15)\end{array}$ & $\begin{array}{l}2.343(2) \\
2.160(3)\end{array}$ & $\begin{array}{l}2.143(2) \\
2.131(3)\end{array}$ \\
\hline $\mathrm{Fe}-\mathrm{Cl}$ & $\begin{array}{l}2.2870(10), \\
2.2769(9)\end{array}$ & $\begin{array}{l}2.2179(7) \\
2.2138(7)\end{array}$ & $\begin{array}{l}2.2209(6) \\
2.2173(6)\end{array}$ & $\begin{array}{l}2.2312(6), \\
2.2227(6)\end{array}$ & $\begin{array}{l}2.2864(9) \\
2.2611(9)\end{array}$ & $\begin{array}{l}2.2225(11) \\
2.2219(11)\end{array}$ \\
\hline
\end{tabular}

${ }^{a}$ For four-coordinate complexes, $\tau_{4}=\left(360^{\circ}-\alpha-\beta\right) /\left(360^{\circ}-2 \theta\right)$; for five-coordinate complexes, $\tau_{5}=(\beta-\alpha) / 60^{\circ} . \alpha$ and $\beta$ are the two largest bond angles around the metal center $(\alpha<\beta)$ and $\theta=109.5^{\circ} .{ }^{46,47}$

Table 4 Electrochemical data for complexes 1-6 ${ }^{a}$

\begin{tabular}{lccc}
\hline & $E_{\mathrm{p}}(\mathrm{ox})$ & $E_{\mathrm{p}}(\mathrm{red})$ & $E_{1 / 2}$ \\
\hline $\mathbf{1}$ & -0.435 & -0.550 & -0.493 \\
$\mathbf{2}$ & -0.448 & -0.616 & -0.532 \\
$\mathbf{3}$ & -0.543 & -0.640 & -0.592 \\
$\mathbf{4}$ & -0.414 & -0.545 & -0.480 \\
$\mathbf{5}$ & -0.477 & -0.575 & -0.526 \\
$\mathbf{6}$ & -0.566 & -0.666 & -0.616 \\
${ }^{a}$ & &
\end{tabular}

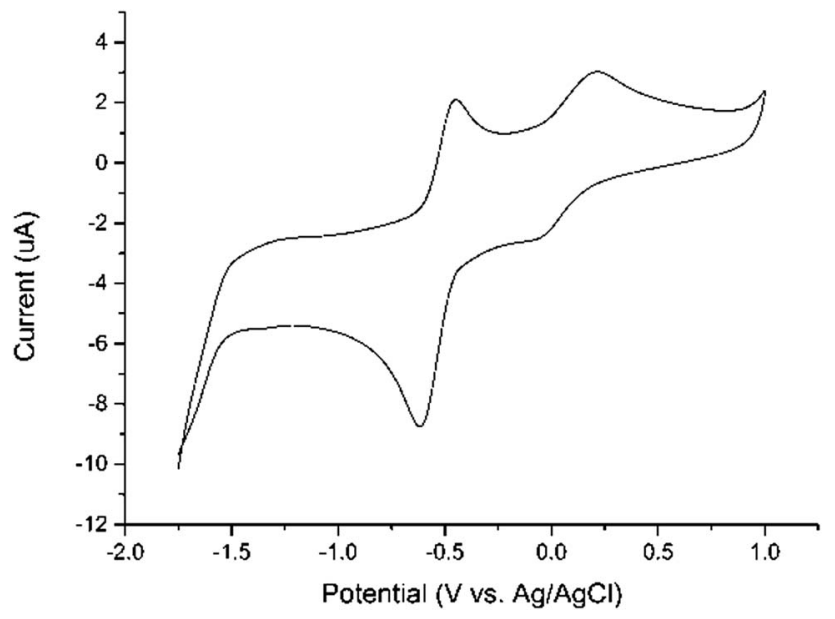

Fig. 2 Cyclic voltammogram of $1.0 \mathrm{mM}$ of 2 in $\mathrm{CH}_{2} \mathrm{Cl}_{2}$ with $0.10 \mathrm{M}$ ${ }^{n} \mathrm{Bu}_{4} \mathrm{NPF}_{6}$ as the supporting electrolyte at a scan rate of $100 \mathrm{mV} \mathrm{s}^{-1}$. The potentials are reported relative to $\mathrm{Ag} / \mathrm{AgCl}$.

conducted by the reaction of equimolar of $\mathrm{Ph}_{2} \mathrm{SiH}_{2}$ and 4-methylbenzaldehyde, and the results are summarized in Table 5. The active catalysts were generated in situ upon the addition of $\mathrm{LiCH}_{2} \mathrm{SiMe}_{3}$ (2 equiv.) to the precursors 1-6. The reaction mixture containing silyl ether products were further converted to the corresponding alcohols by treatment of tetra- $n$ butylammonium fluoride (TBAF) solution. Such precatalyst activation strategy and product workup process have been employed in similar catalytic systems. ${ }^{21}$ The results were analyzed by ${ }^{1} \mathrm{H}$ NMR spectroscopy using $1,3,5-$
Table 5 Precatalysts 1-6 for hydrosilylation of 4-methylbenzaldehyde with $\mathrm{Ph}_{2} \mathrm{SiH}_{2}{ }^{a}$

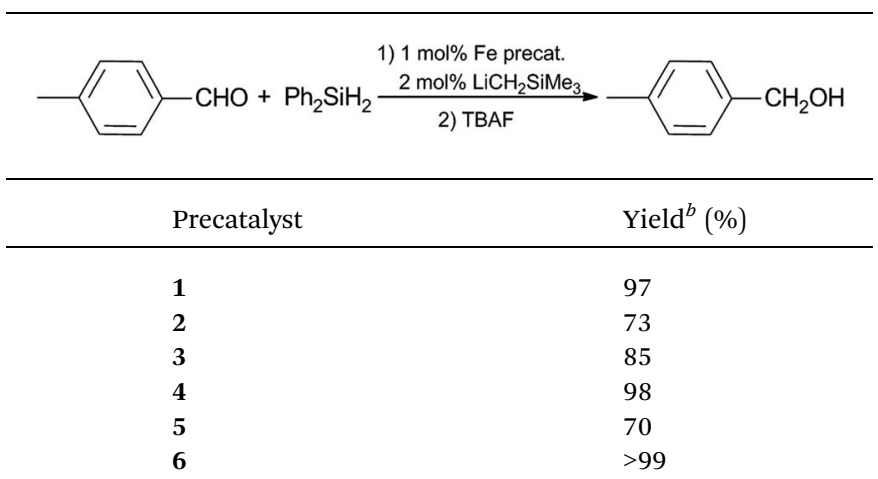

${ }^{a}$ Reaction conditions: (1) 4-methylbenzaldehyde (1.0 mmol), $\mathrm{Ph}_{2} \mathrm{SiH}_{2}$ (1.0 mmol), $1 \mathrm{~mol} \%$ Fe precatalyst, $2 \mathrm{~mol} \% \mathrm{LiCH}_{2} \mathrm{SiMe}_{3}$, toluene, $25{ }^{\circ} \mathrm{C}, 1 \mathrm{~h}$; (2) TBAF, THF, 6 h. ${ }^{b}$ Yields were determined by ${ }^{1} \mathrm{H}$ NMR with an internal standard.

trimethoxybenzene as an internal standard. As can be seen in Table 5, all six BIAN-supported ferrous complexes can serve as efficient precatalysts for the room-temperature hydrosilylation reaction. The difference in reactivity of 1-6 in the test reaction seems to be not very significant, judged by the yield of alcohol products, with compound 6 showing most promising performance. This implies that the differences in electronic property and steric bulk for 1-6 do not affect their catalytic reactivity very much, which is in sharp contrast to a previously reported series of palladium diimine complexes for catalytic ethylene polymerization. ${ }^{48}$ Thus, further optimization of catalytic reaction conditions and result discussions will be focused on complex 6 .

Further screening of the reaction was performed by variation of the type and amount of silane used, as well as the reaction time (Table 6). Employment of alternative silanes resulted in lower yields of alcohols in comparison to that with $\mathrm{Ph}_{2} \mathrm{SiH}_{2}$ (entry 1-4). In addition, increasing the amount of $\mathrm{Ph}_{2} \mathrm{SiH}_{2}$ to 1.5 or 2.0 equivalent led to lower yields of the product (entry 5 and 6). The reaction time was also optimized using conditions listed in Table 6 (entry 7-9), which demonstrates that the catalytic reaction reaches completion by 1 hour and the determined yield of alcohol product further decreases as the reaction time is extended. On this basis, we opted to use 1.0 equiv. of $\mathrm{Ph}_{2} \mathrm{SiH}_{2}$ 
Table 6 Preliminary screening of catalytic reaction conditions ${ }^{a}$

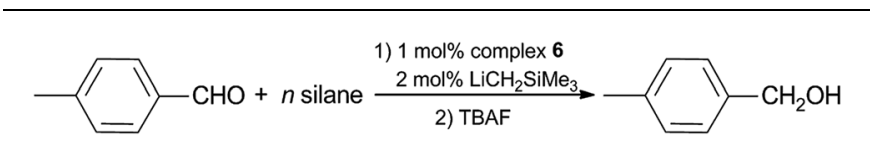

\begin{tabular}{lllcl}
\hline Entry & Silane & $n$ & Time (h) & Yield $^{b}(\%)$ \\
\hline 1 & $\mathrm{PhSiH}_{3}$ & 1.0 & 1.0 & 72 \\
2 & $\mathrm{Ph}_{3} \mathrm{SiH}$ & 1.0 & 1.0 & 70 \\
3 & $\mathrm{Et}_{3} \mathrm{SiH}$ & 1.0 & 1.0 & 45 \\
4 & $(\mathrm{EtO})_{3} \mathrm{SiH}$ & 1.0 & 1.0 & 68 \\
5 & $\mathrm{Ph}_{2} \mathrm{SiH}_{2}$ & 1.5 & 1.0 & 73 \\
6 & $\mathrm{Ph}_{2} \mathrm{SiH}_{2}$ & 2.0 & 1.0 & 60 \\
7 & $\mathrm{Ph}_{2} \mathrm{SiH}_{2}$ & 1.0 & 0.5 & 71 \\
8 & $\mathrm{Ph}_{2} \mathrm{SiH}_{2}$ & 1.0 & 3.0 & 95 \\
9 & $\mathrm{Ph}_{2} \mathrm{SiH}_{2}$ & 1.0 & 12.0 & 74
\end{tabular}

${ }^{a}$ Reaction conditions: (1) 4-methylbenzaldehyde (1.0 mmol), silane ( mmol), $1 \mathrm{~mol} \%$ complex 6, $2 \mathrm{~mol} \% \mathrm{LiCH}_{2} \mathrm{SiMe}_{3}$, toluene, $25{ }^{\circ} \mathrm{C}$; (2) TBAF, THF, $6 \mathrm{~h} .{ }^{b}$ Yields were determined by ${ }^{1} \mathrm{H}$ NMR with an internal standard.

and 1 hour reaction time as our so-far optimized condition for further exploration of reaction scope for other functionalized aldehydes and ketones. It was found that a number of
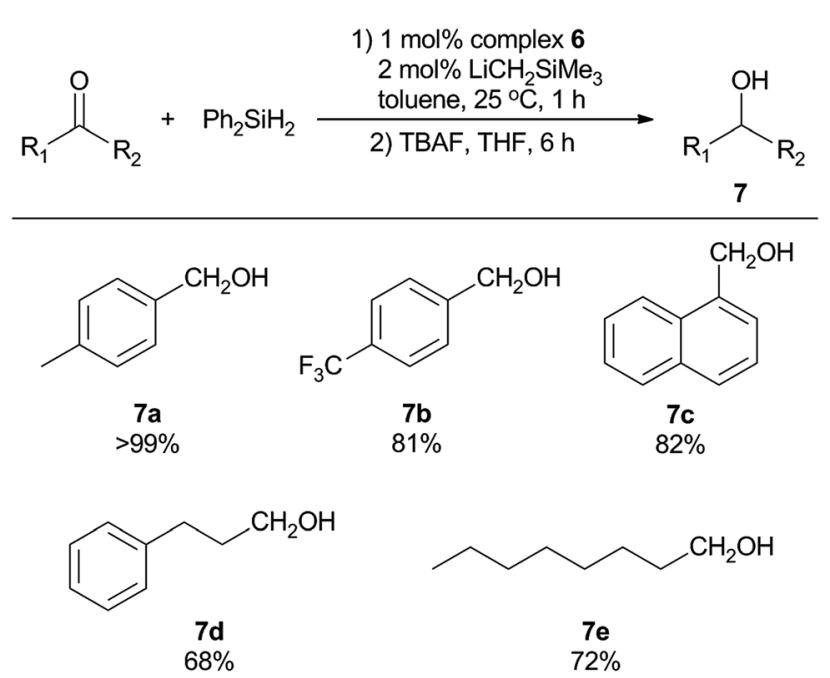<smiles>COc1ccc(C(C)O)cc1</smiles><smiles>CCC(O)c1ccccc1</smiles><smiles>CC(O)CCc1ccccc1</smiles><smiles>OC(C1CCCCC1)C1CCCCC1</smiles>

Scheme 2 Hydrosilylation of functionalized aldehydes and ketones by complex 6. substrates could be successfully accommodated, as summarized in Scheme 2. para-Substituted benzaldehydes bearing either electron-donating or electron-withdrawing substituents were successfully converted to the corresponding primary alcohols ( $7 \mathbf{a}$ and $\mathbf{7 b}$ ). In addition, sterically bulkier aromatic aldehyde was reduced in good yield (7c). In contrast, the transformation of aliphatic aldehydes into the primary alcohol counterparts ( $\mathbf{7 d}$ and $7 \mathbf{e}$ ) was not as efficient using the same catalytic protocol. The production of secondary alcohols using various ketones was also investigated. Substituted acetophenone derivatives were reduced to the related alcohols in moderate to good yields ( $\mathbf{7} \mathbf{f}$ and $\mathbf{7 g}$ ), demonstrating that an electron-withdrawing group is more favorable for the reaction. Propiophenone was converted to the corresponding secondary alcohol $7 \mathbf{h}$ in a lower yield, possibly due to the increased steric bulk of the alkyl group. Unlike the aldehyde counterparts, structurally diverse dialkyl ketones were suitable substrates for this catalytic system, resulting in high yields of dialkyl alcohols (7i and $7 \mathbf{j})$. Thus, this preliminary catalytic reactivity investigation showed that the sterically hindered asymmetric (BIAN)$\mathrm{FeCl}_{2}$ complexes are versatile precatalysts for room-temperature hydrosilylation of aldehydes and ketones. The detailed mechanism of this catalytic system is not fully elucidated yet. Other than the more obvious Fe-mediated process, a recent study showed that BIAN ligands could be dearomatized by reactive sblock alkyls such as $\mathrm{LiCH}_{2} \mathrm{SiMe}_{3}$, and the resulting species are catalytically active towards hydroamination reactions. ${ }^{49}$

\section{Conclusions}

In summary, we have prepared a series of iron complexes ligated by asymmetric bulky BIAN ligands. The solid-state structures of these complexes were determined by X-ray crystallography, showing either 4- or 5-coordinate iron centers. These compounds represent very rare examples of structurally characterized iron complexes with asymmetric bidentate BIAN ligands. The structural parameters of the BIAN ligand backbones reveal that the ligands remain in their neutral form in these complexes. The compounds were also characterized by ${ }^{1} \mathrm{H}$ NMR, IR, UV-vis spectroscopy and cyclic voltammetry. The electrochemical measurements showed that this series of compounds undergo quasi-reversible 2-electron reduction of the complexes, rather than two successive 1e reduction on the ligand. Such synergistic reactivity of both ligand and metal center makes them possible precatalysts for $2 \mathrm{e}$ reduction of carbonyl compounds. Preliminary catalytic performance screening found that these compounds exhibited good catalytic reactivity for the room-temperature hydrosilylation of various aldehydes and ketones. Mechanistic investigation and further improvement of this catalytic system via ligand modification are ongoing and will be reported in due course.

\section{Experimental}

\section{Materials and methods}

All reactions were performed under a nitrogen atmosphere with rigorous exclusion of oxygen and water using standard Schlenk 
or glovebox techniques. All solvents were dried and purified using an Innovative Technology PureSolv MD5 solvent purification system. Ligands $\mathbf{A r}-\mathbf{B I A N} \mathbf{N}^{\mathbf{X}}$ were prepared following literature procedures. ${ }^{\mathbf{4 2 , 4 4 , 4 5}}$ All other reagents were obtained commercially and used as received. UV-vis spectra were recorded on a Shimadzu UV-3600 UV-vis-NIR spectrophotometer in THF solution. Infrared spectra were measured as Nujol mulls between $\mathrm{KBr}$ plates on a Nicolet 6700 spectrometer. ${ }^{1} \mathrm{H}$ NMR $(300 \mathrm{MHz})$ spectra were collected using a Bruker Avance III 300 spectrometer and referenced internally to the residual solvent resonances. Cyclic voltammograms were obtained using a $\mathrm{CH}$ Instruments $\mathrm{CHI}-660 \mathrm{D}$ electrochemical analyzer in $0.10 \mathrm{M}$ $\mathrm{CH}_{2} \mathrm{Cl}_{2}$ solution of ${ }^{n} \mathrm{Bu}_{4} \mathrm{NPF}_{6}$, with Pt working and auxiliary electrodes, $\mathrm{Ag} / \mathrm{AgCl}$ reference electrode, and a scan rate of $100 \mathrm{mV} \mathrm{s}^{-1}$. Melting points were measured on a Mel-Temp II apparatus and uncorrected, using glass capillaries sealed under inert atmosphere. Elemental analyses were performed by an Elementar Vario EL elemental analyzer.

\section{Synthesis of (Dipp-BIAN $\left.{ }^{\mathrm{F}}\right) \mathrm{FeCl}_{2}(1)$}

To a stirred THF suspension of anhydrous $\mathrm{FeCl}_{2}(0.412 \mathrm{~g}, 3.25$ mmol), a THF solution of Dipp-BIAN ${ }^{\mathrm{F}}$ ligand $(3.009 \mathrm{~g}, 3.92$ $\mathrm{mmol}$ ) was added dropwise at ambient temperature. The solution gradually turned to dark reddish brown and the resulting mixture was stirred overnight. Solvents were partially removed under reduced pressure, and the precipitated product was isolated by decantation, washed with toluene, and dried under vacuum. Yield: $2.72 \mathrm{~g}$ (94\%). Mp: >320 ${ }^{\circ} \mathrm{C} .{ }^{1} \mathrm{H}$ NMR $(300 \mathrm{MHz}$, $\mathrm{CDCl}_{3}, 23{ }^{\circ} \mathrm{C}, \delta$ in ppm): $12.62,9.38,8.14,6.36,5.79,3.82,2.91$, $1.95,1.34,-0.84,-3.27,-4.70,-15.62$. UV-vis, $\lambda_{\max }$ in $\mathrm{nm}(\varepsilon$, $\left.\mathrm{M}^{-1} \mathrm{~cm}^{-1}\right): 316\left(7.8 \times 10^{3}\right), 425(\mathrm{sh})$. IR (Nujol, $\nu(\mathrm{C}=\mathrm{N})$ in $\mathrm{cm}^{-1}$ ): 1619, 1582. Anal calcd for $\mathrm{C}_{56} \mathrm{H}_{47} \mathrm{Cl}_{2} \mathrm{FFeN}_{2}$ (found): $\mathrm{C}$, 75.26 (75.09); H, 5.30 (5.43); N, 3.13 (2.86).

\section{Synthesis of (Dipp-BIAN $\left.{ }^{\mathrm{Cl}}\right) \mathrm{FeCl}_{2}$ (2)}

To a stirred THF suspension of anhydrous $\mathrm{FeCl}_{2}(0.444 \mathrm{~g}, 3.50$ $\mathrm{mmol}$ ), a THF solution of Dipp-BIAN ${ }^{\mathrm{Cl}}$ ligand $(2.623 \mathrm{~g}, 3.35$ $\mathrm{mmol}$ ) was added dropwise at ambient temperature. The solution gradually turned to dark yellowish brown and the resulting mixture was stirred overnight. The suspension was filtered and all volatiles were removed under reduced pressure. The yellowish brown solid product was washed with toluene and dried under vacuum. Yield: $2.44 \mathrm{~g}$ (80\%). Mp: $>320{ }^{\circ} \mathrm{C} .{ }^{1} \mathrm{H} \mathrm{NMR}$ (300 MHz, $\mathrm{CDCl}_{3}, 23{ }^{\circ} \mathrm{C}, \delta$ in ppm): 12.51, 9.32, 8.17, 6.41, 5.64, $3.82,2.87,1.91,1.28,-0.70,-3.37,-4.78,-5.81,-15.50$. UVvis, $\lambda_{\max }$ in $\mathrm{nm}\left(\varepsilon, \mathrm{M}^{-1} \mathrm{~cm}^{-1}\right): 313\left(8.5 \times 10^{3}\right), 425$ (sh). IR (Nujol, $\nu\left(\mathrm{C}=\mathrm{N}\right.$ ) in $\left.\mathrm{cm}^{-1}\right)$ : 1621 , 1584. Anal calcd for $\mathrm{C}_{56} \mathrm{H}_{47^{-}}$ $\mathrm{Cl}_{3} \mathrm{FeN}_{2}$ (found): C, 73.90 (73.61); H, 5.20 (5.39); N, 3.08 (3.38).

\section{Synthesis of (Dipp-BIAN ${ }^{\mathrm{Me}}$ ) $\mathrm{FeCl}_{2}$ (3)}

To a stirred THF suspension of anhydrous $\mathrm{FeCl}_{2}(0.124 \mathrm{~g}, 0.98$ $\mathrm{mmol})$, a THF solution of Dipp-BIAN ${ }^{\mathrm{Me}}$ ligand $(0.730 \mathrm{~g}, 0.96$ mmol) was added dropwise at ambient temperature. The solution gradually turned to dark brown and the resulting mixture was stirred overnight. The suspension was filtered and all volatiles were removed under reduced pressure. The greenish yellow solid product was washed with toluene and dried under vacuum. Yield: $0.854 \mathrm{~g}$ (85\%). Mp: $>320{ }^{\circ} \mathrm{C}$. ${ }^{1} \mathrm{H}$ NMR $(300 \mathrm{MHz}$, $\mathrm{CDCl}_{3}, 23{ }^{\circ} \mathrm{C}, \delta$ in ppm): 16.45, 12.98, 12.64, 9.30, 8.16, 6.49, 6.32, 5.82, 5.07, 3.78, 2.96, 2.39, 1.88, 1.28, -1.02, -2.97, -5.14, -15.74. UV-vis, $\lambda_{\max }$ in $\mathrm{nm}\left(\varepsilon, \mathrm{M}^{-1} \mathrm{~cm}^{-1}\right): 312\left(7.0 \times 10^{3}\right), 422$ (sh). IR (Nujol, $\nu\left(\mathrm{C}=\mathrm{N}\right.$ ) in $\left.\mathrm{cm}^{-1}\right): 1622,1585$. Anal calcd for $\mathrm{C}_{57} \mathrm{H}_{50} \mathrm{Cl}_{2} \mathrm{FeN}_{2}$ (found): C, 76.94 (75.54); H, 5.66 (5.89); N, 3.15 (3.02).

\section{Synthesis of $\left(\right.$ Mes-BIAN $\left.^{\mathrm{F}}\right) \mathrm{FeCl}_{2}$ (4)}

To a stirred THF suspension of anhydrous $\mathrm{FeCl}_{2}(0.210 \mathrm{~g}, 1.65$ mmol), a THF solution of Mes-BIAN ${ }^{\mathrm{F}}$ ligand $(1.171 \mathrm{~g}, 1.61$ mmol) was added dropwise at ambient temperature. The solution gradually turned to dark brown and the resulting mixture was stirred overnight. Solvents were partially removed under reduced pressure, and the precipitated yellowish brown product was isolated by decantation, washed with toluene, and dried under vacuum. Yield: $0.923 \mathrm{~g}$ (62\%). Mp: >320 ${ }^{\circ} \mathrm{C} .{ }^{1} \mathrm{H}$ NMR $(300$ $\mathrm{MHz}, \mathrm{CDCl}_{3}, 23{ }^{\circ} \mathrm{C}, \delta$ in ppm): 15.71, 14.74, 13.25, 12.52, 9.31, 8.25, 6.41, 6.23, 5.07, 3.79, 2.39, 1.88, 1.32, -3.60, -5.89. UV-vis, $\lambda_{\max }$ in $\mathrm{nm}\left(\varepsilon, \mathrm{M}^{-1} \mathrm{~cm}^{-1}\right): 323\left(9.0 \times 10^{3}\right), 418$ (sh). IR (Nujol, $\nu(\mathrm{C}=\mathrm{N})$ in $\left.\mathrm{cm}^{-1}\right): 1619$, 1587. Anal calcd for $\mathrm{C}_{53} \mathrm{H}_{41} \mathrm{Cl}_{2} \mathrm{FFeN}_{2}$ (found): C, 74.74 (75.69); H, 4.85 (5.00); N, 3.29 (2.83).

\section{Synthesis of (Mes-BIAN $\left.{ }^{\mathrm{Cl}}\right) \mathrm{FeCl}_{2}(5)$}

To a stirred THF suspension of anhydrous $\mathrm{FeCl}_{2}(0.221 \mathrm{~g}, 1.74$ mmol), a THF solution of Mes-BIAN ${ }^{\mathrm{Cl}}$ ligand (1.283 g, 1.73 $\mathrm{mmol}$ ) was added dropwise at ambient temperature. The solution gradually turned to dark brown and the resulting mixture was stirred overnight. The solution was concentrated under reduced pressure and $50 \mathrm{~mL}$ of hexanes was added. The precipitated greenish yellow product was isolated by decantation and dried under vacuum. Yield: $1.42 \mathrm{~g}$ (87\%). Mp: $>320{ }^{\circ} \mathrm{C}$. ${ }^{1} \mathrm{H}$ NMR (300 MHz, $\mathrm{CDCl}_{3}, 23{ }^{\circ} \mathrm{C}, \delta$ in ppm): 15.77, 14.67, 13.19, 12.48, 9.31, 8.24, 6.73, 6.47, 6.29, 5.07, 3.83, 2.34, 1.91, -3.70, -6.03. UV-vis, $\lambda_{\max }$ in $\mathrm{nm}\left(\varepsilon, \mathrm{M}^{-1} \mathrm{~cm}^{-1}\right): 322\left(8.2 \times 10^{3}\right), 418$ (sh). IR (Nujol, $\nu\left(\mathrm{C}=\mathrm{N}\right.$ ) in $\left.\mathrm{cm}^{-1}\right)$ : 1623, 1588. Anal calcd for $\mathrm{C}_{53} \mathrm{H}_{41} \mathrm{Cl}_{3} \mathrm{FeN}_{2}$ (found): C, 73.33 (72.71); $\mathrm{H}, 4.76$ (4.68); N, 3.23 (2.92).

\section{Synthesis of (Mes-BIAN $\left.{ }^{\mathrm{Me}}\right) \mathrm{FeCl}_{2}$ (6)}

To a stirred THF suspension of anhydrous $\mathrm{FeCl}_{2}(0.343 \mathrm{~g}, 2.71$ $\mathrm{mmol}$ ), a THF solution of Mes-BIAN ${ }^{\mathrm{Me}}$ ligand (1.918 g, 2.67 $\mathrm{mmol}$ ) was added dropwise at ambient temperature. The solution gradually turned to dark reddish brown and the resulting mixture was stirred overnight. The suspension was filtered and all volatiles were removed under reduced pressure. The dark brown solid product was washed with toluene and dried under vacuum. Yield: $1.972 \mathrm{~g}$ (80\%). Mp: $>320{ }^{\circ} \mathrm{C}$. ${ }^{1} \mathrm{H}$ NMR $(300 \mathrm{MHz}$, $\mathrm{CDCl}_{3}, 23{ }^{\circ} \mathrm{C}, \delta$ in ppm): 16.81, 15.82, 14.89, 13.39, 12.60, 9.35, $8.28,6.25,5.54,5.27,2.40,1.30,-3.26,-4.08,-5.39$. UV-vis, $\lambda_{\max }$ in $\mathrm{nm}\left(\varepsilon, \mathrm{M}^{-1} \mathrm{~cm}^{-1}\right): 324\left(8.1 \times 10^{3}\right), 422(\mathrm{sh})$. IR (Nujol, $\nu(\mathrm{C}=\mathrm{N})$ in $\left.\mathrm{cm}^{-1}\right)$ : 1621, 1586. Anal calcd for $\mathrm{C}_{54} \mathrm{H}_{44} \mathrm{Cl}_{2} \mathrm{FeN}_{2}$ (found): C, 76.51 (76.64); H, 5.23 (5.09); N, 3.33 (2.98). 


\section{X-ray crystallography}

Single crystals of 1-6 suitable for X-ray crystallography were grown by vapor diffusion of hexanes into a THF solution of the compound. Data for 1 and 2 were collected on a Rigaku XtaLAB P300DS diffractometer with $\mathrm{Cu} \mathrm{K} \alpha$ radiation $(\lambda=1.54178 \AA)$ at $93 \mathrm{~K}$, data for 3-5 were collected on a Rigaku Supernova diffractometer with $\mathrm{Cu} \mathrm{K} \alpha$ radiation $(\lambda=1.54178 \AA)$ at $150 \mathrm{~K}$, and data for 6 were collected on a Rigaku Supernova diffractometer with Mo $\mathrm{K} \alpha$ radiation $(\lambda=0.71073 \AA)$ at $150 \mathrm{~K}$. The empirical absorption corrections were applied using spherical harmonics, implemented in the SCALE3 ABSPACK scaling algorithm. $^{50}$ All the structures were solved using direct methods, which yielded the positions of all non-hydrogen atoms. Hydrogen atoms were placed in calculated positions in the final structure refinement. Structure determination and refinement were carried out using SHELXS and SHELXL programs, respectively. ${ }^{51}$ The PLATON SQUEEZE treatment was applied to all guest molecules in the structure of $\mathbf{6}$ because the guest molecules are extremely disordered and cannot be modeled. CCDC-1530840 (1), 1530844 (2), 1530839 (3), 1530842 (4), 1530841 (5), 1530843 (6) contain the supplementary crystallographic data for this paper. $\dagger$

\section{Typical procedure for catalytic hydrosilylation of aldehydes and ketones}

In a glove box, a $20 \mathrm{~mL}$ vial containing a stir bar was charged with complex 6 (8.5 mg, $1 \mathrm{~mol} \%)$ and cooled to $-35{ }^{\circ} \mathrm{C}$. A toluene solution of $\mathrm{LiCH}_{2} \mathrm{SiMe}_{3}(0.01 \mathrm{M}, 2.0 \mathrm{~mL}, 2 \mathrm{~mol} \%)$ was then added to the vial, and the reaction mixture was allowed to warm up under stirring for $0.5 \mathrm{~h}$. Subsequently, substrate (1.0 mmol) and $\mathrm{Ph}_{2} \mathrm{SiH}_{2}(186 \mu \mathrm{L}, 1.0 \mathrm{mmol})$ were added. The resulting mixture was stirred for $1 \mathrm{~h}$ at ambient temperature. After that, the vial was removed from the glovebox, and the reaction mixture was treated with $2 \mathrm{~mL}$ of $\mathrm{THF}$ and $1 \mathrm{~mL}$ of 1.0 M THF solution of tetra- $n$-butylammonium fluoride. After the mixture was stirred for $6 \mathrm{~h}$, all volatiles were removed under vacuum and the residue was extracted with $\mathrm{CH}_{2} \mathrm{Cl}_{2}$. The organic phase was separated, dried with $\mathrm{MgSO}_{4}$, filtered and concentrated. The obtained residue was analyzed by ${ }^{1} \mathrm{H}$ NMR method using 1,3,5-trimethoxybenzene as an internal standard.

\section{Acknowledgements}

We gratefully acknowledge financial support from the National Natural Science Foundation of China (No. 21301070), Pearl River S\&T Nova Program of Guangzhou (No. 201610010118), the Fundamental Research Funds for the Central Universities (No. 21615401), Natural Science Foundation of Guangdong Province (No. 2016A030313093), China Postdoctoral Science Foundation (No. 2016M592598) and Jinan University.

\section{Notes and references}

1 W. Kaim, Inorg. Chem., 2011, 50, 9752-9765.

2 W. Kaim, Eur. J. Inorg. Chem., 2012, 343-348.
3 V. K. K. Praneeth, M. R. Ringenberg and T. R. Ward, Angew. Chem., Int. Ed., 2012, 51, 10228-10234.

4 O. R. Luca and R. H. Crabtree, Chem. Soc. Rev., 2013, 42, 1440-1459.

5 D. L. J. Broere, R. Plessius and J. I. van der Vlugt, Chem. Soc. Rev., 2015, 44, 6886-6915.

6 V. Lyaskovskyy and B. de Bruin, ACS Catal., 2012, 2, 270-279.

7 L. A. Berben, Chem.-Eur. J., 2015, 21, 2734-2742.

8 G. V. Koten and K. Vrieze, Adv. Organomet. Chem., 1982, 21, 151-239.

9 A. Raghavan and A. Venugopal, J. Coord. Chem., 2014, 67, 2530-2549.

10 N. J. Hill, I. Vargas-Baca and A. H. Cowley, Dalton Trans., 2009, 240-253.

11 C. J. Allan, B. F. T. Cooper, H. J. Cowley, J. M. Rawson and C. L. B. Macdonald, Chem.-Eur. J., 2013, 19, 14470-14483.

12 A. L. Brazeau, N. D. Jones and P. J. Ragogna, Dalton Trans., 2012, 41, 7890-7896.

13 N. J. Hill, G. Reeske, J. A. Moore and A. H. Cowley, Dalton Trans., 2006, 4838-4844.

14 J. Wang, R. Ganguly, L. Yongxin, J. Díaz, H. S. Soo and F. García, Dalton Trans., 2016, 45, 7941-7946.

15 R. A. Zarkesh, A. S. Ichimura, T. C. Monson, N. C. Tomson and M. R. Anstey, Dalton Trans., 2016, 45, 9962-9969.

16 K. M. Clark, Inorg. Chem., 2016, 55, 6443-6448.

17 J. Bendix and K. M. Clark, Angew. Chem., Int. Ed., 2016, 55, 2748-2752.

18 B. A. Schaefer, G. W. Margulieux, B. L. Small and P. J. Chirik, Organometallics, 2015, 34, 1307-1320.

19 B. M. Schmiege, M. J. Carney, B. L. Small, D. L. Gerlach and J. A. Halfen, Dalton Trans., 2007, 2547-2562.

20 F. S. Wekesa, R. Arias-Ugarte, L. Kong, Z. Sumner, G. P. McGovern and M. Findlater, Organometallics, 2015, 34, 5051-5056.

21 M. J. Supej, A. Volkov, L. Darko, R. A. West, J. M. Darmon, C. E. Schulz, K. A. Wheeler and H. M. Hoyt, Polyhedron, 2016, 114, 403-414.

22 I. L. Fedushkin, A. A. Skatova, N. M. Khvoinova, A. N. Lukoyanov, G. K. Fukin, S. Y. Ketkov, M. O. Maslov, A. S. Bogomyakov and V. M. Makarov, Russ. Chem. Bull., 2013, 62, 2122-2131.

23 D. A. Piryazev, M. A. Ogienko, A. V. Virovets, N. A. Pushkarevsky and S. N. Konchenko, Acta Crystallogr., Sect. C: Cryst. Struct. Commun., 2012, 68, m320-m322.

24 B. Marciniec, Hydrosilylation: A Comprehensive Review on Recent Advances, Springer Science, Berlin, 2009.

25 K. Junge, K. Schröder and M. Beller, Chem. Commun., 2011, 47, 4849-4859.

26 S. Enthaler, K. Junge and M. Beller, Angew. Chem., Int. Ed., 2008, 47, 3317-3321.

27 B. Su, Z.-C. Cao and Z.-J. Shi, Acc. Chem. Res., 2015, 48, 886896.

28 I. Bauer and H.-J. Knölker, Chem. Rev., 2015, 115, 3170-3387.

29 N. S. Shaikh, K. Junge and M. Beller, Org. Lett., 2007, 9, 54295432.

30 H. Nishiyama and A. Furuta, Chem. Commun., 2007, 760-762. 
31 P. Bhattacharya, J. A. Krause and H. Guan, Organometallics, 2011, 30, 4720-4729.

32 A. M. Tondreau, E. Lobkovsky and P. J. Chirik, Org. Lett., 2008, 10, 2789-2792.

33 A. M. Tondreau, J. M. Darmon, B. M. Wile, S. K. Floyd, E. Lobkovsky and P. J. Chirik, Organometallics, 2009, 28, 3928-3940.

34 J. Yang and T. D. Tilley, Angew. Chem., Int. Ed., 2010, 49, 10186-10188.

35 T. Bleith, H. Wadepohl and L. H. Gade, J. Am. Chem. Soc., 2015, 137, 2456-2459.

36 T. Bleith and L. H. Gade, J. Am. Chem. Soc., 2016, 138, 49724983.

37 Á. Raya-Barón, M. A. Ortuño, P. Oña-Burgos, A. RodríguezDiéguez, R. Langer, C. J. Cramer, I. Kuzu and I. Fernández, Organometallics, 2016, 35, 4083-4089.

38 A. J. Ruddy, C. M. Kelly, S. M. Crawford, C. A. Wheaton, O. L. Sydora, B. L. Small, M. Stradiotto and L. Turculet, Organometallics, 2013, 32, 5581-5588.

39 J. L. Rhinehart, N. E. Mitchell and B. K. Long, ACS Catal., 2014, 4, 2501-2504.

40 S. Du, S. Kong, Q. Shi, J. Mao, C. Guo, J. Yi, T. Liang and W.-H. Sun, Organometallics, 2015, 34, 582-590.
41 X. Wang, L. Fan, Y. Yuan, S. Du, Y. Sun, G. A. Solan, C.-Y. Guo and W.-H. Sun, Dalton Trans., 2016, 45, 18313-18323.

42 H. Liu, W. Zhao, X. Hao, C. Redshaw, W. Huang and W.-H. Sun, Organometallics, 2011, 30, 2418-2424.

43 Q. Ban, J. Zhang, T. Liang, C. Redshaw and W.-H. Sun, J. Organomet. Chem., 2012, 713, 151-156.

44 S. Kong, C.-Y. Guo, W. Yang, L. Wang, W.-H. Sun and R. Glaser, J. Organomet. Chem., 2013, 725, 37-45.

45 L. Fan, S. Du, C.-Y. Guo, X. Hao and W.-H. Sun, J. Polym. Sci., Part A: Polym. Chem., 2015, 53, 1369-1378.

46 L. Yang, D. R. Powell and R. P. Houser, Dalton Trans., 2007, 955-964.

47 A. W. Addison, T. N. Rao, J. Reedijk, J. van Rijn and G. C. Verschoor, J. Chem. Soc., Dalton Trans., 1984, 13491356.

48 S. Dai, X. Sui and C. Chen, Angew. Chem., Int. Ed., 2015, 54, 9948-9953.

49 M. Arrowsmith, M. S. Hill and G. Kociok-Köhn, Organometallics, 2014, 33, 206-216.

50 CrysAlis Pro, Version 1.171.38.43, Rigaku OD, 2015.

51 G. M. Sheldrick, Acta Crystallogr., Sect. C: Struct. Chem., 2015, 71, 3-8. 